\title{
Surface and upper air meteorological features during onset phase of 2003 monsoon
}

\author{
O P Singh*, H R Hatwar and ONKARI PRASAD \\ India Meteorological Department, Mausam Bhavan, Lodhi Road, New Delhi 110 003, India. \\ *e-mail: opsingh@imdmail.gov.in
}

\begin{abstract}
The second campaign of the Arabian Sea Monsoon Experiment (ARMEX-II) was conducted in two phases viz., March-April and May-June 2003. In the present work, the buoy and ocean research vessel data collected during the second phase of ARMEX-II have been analysed to bring out the characteristic features of monsoon onset. The results have shown that the thermodynamical features such as build up of lower tropospheric instability and increased height of zero degree isotherm occurred about a week before the monsoon onset over Kerala and adjoining southeast Arabian Sea. There was a sharp fall in the temperature difference between 850 and $500 \mathrm{hPa}$, and the height of zero degree isotherm about 2-3 days before the monsoon onset. The flux of sensible heat was positive (sea to air) over south Arabian Sea during the onset phase. Over the Bay of Bengal higher negative (air to sea) values of sensible flux prevailed before the monsoon onset which became less negative with the advance of monsoon over that region.

The pre-onset period was characterized by large sea surface temperature (SST) gradient over the Arabian Sea with rapid decrease towards north of the warm pool region. The buoy observations have shown that SST remained close to $30.5^{\circ} \mathrm{C}$ in the warm pool region during the pre-onset period in 2003 but only 2-3 degrees away (north of this region) SSTs were as low as $28.5-29^{\circ} \mathrm{C}$. An interesting aspect of sea level pressure (SLP) variability over the Indian seas during the onset phase of summer monsoon 2003 was undoubtedly, the highest SLP in the warm pool region inspite of very high SSTs.
\end{abstract}

\section{Introduction}

The Arabian Sea Monsoon Experiment-II (ARMEX-II), the second observational campaign of ARMEX under the Indian Climate Research Programme (ICRP) was conducted in 2003 during March-June. One of the main objectives of ARMEX-II campaign was the collection of high quality data for the study of monsoon onset processes. The present work aims at gaining more insight into the monsoon onset processes utilizing ARMEX-II data, especially the thermodynamical structure of the troposphere and air-sea interaction characteristics over the sea areas during pre-onset and onset periods of the summer monsoon 2003.
The characteristics of surface and upper air features in the warm pool region have also been paid special attention using the data collected onboard Ocean Research Vessel (ORV) Sagar Kanya and the array of meteorological buoys deployed over the Arabian Sea and the Bay of Bengal.

Earlier monsoon experiments have enabled the collection of detailed observations from the region of the onset vortex and warm pool in the southeast Arabian Sea (Krishnamurti et al 1981; Kershaw 1985; Singh and Hatwar 2005). Pearce and Mohanty (1984) have reported moisture build up over the Arabian Sea before monsoon onset. Sikka (2005) has provided a lucid review of major advances in the monsoon meteorology during the

Keywords. Arabian Sea Monsoon Experiment (ARMEX); summer monsoon; sea surface temperature (SST); zero degree isotherm; warm pool; sensible heat flux. 
last four decades. The initial results of ARMEX had brought out several features of Arabian Sea warm pool (Chowdary et al 2005; Gnanaseelan et al 2005; Hareesh Kumar et al 2005; Shenoi et al 2005 ) but there was a need for more detailed analyses of surface and upper air features in the Arabian Sea and the Bay of Bengal during the onset phase of the monsoon. For instance, the air-sea interaction processes over the Arabian Sea and the Bay of Bengal needed to be studied in association with the monsoon advance. Similarly, the thermodynamical characteristics of atmosphere over the warm pool region required investigation in connection with the variabilities of surface parameters like SST, SLP, etc. The results presented here provide some new insights into the monsoon onset processes over the Arabian Sea and the Bay of Bengal.

The investigation of air-sea interaction characteristics especially over south Arabian Sea and Bay of Bengal during the onset phase of monsoon was one of the main objectives of ARMEX. A few initial results (Gopala Reddy et al 2005; Murthy and Sivaramakrishnan 2005) have been reported but more comprehensive analyses of ARMEX data were required to bring out the contrasting features of air-sea interaction processes over the Arabian Sea and the Bay of Bengal.

\section{Data and methodology}

\subsection{Surface and upper air data collected onboard ORV Sagar Kanya}

The cruise track of ORV Sagar Kanya was planned in the Arabian Sea from 21 May to 18 June, 2003 to cover the monsoon onset phase. Surface and upper air observations including radiosonde and upper wind observations commenced over the southeast Arabian Sea on 21 May. The ship was stationed close to the Kerala coast from 24 May to 7 June where crucial data were collected for the study of monsoon onset processes. After the onset of monsoon on 8 June the ship sailed northward and kept taking useful observations from the leading edge of the monsoon during its further advance over the Arabian Sea and west coast of India. In the present study, the entire surface and upper air data collected onboard ORV Sagar Kanya have been utilized. The thermodynamical parameters like height of zero degree isotherm and lapse rate in lower and middle troposphere have been obtained from the radiosonde data collected over the sea areas. Lower tropospheric winds over the Arabian Sea have been obtained from the upper wind observations of Sagar Kanya.

\subsection{Buoy data}

The two arrays of meteorological buoys comprising south to north array in the Arabian Sea and southwest to northeast array in the Bay of Bengal were deployed to collect simultaneous surface observations in the Arabian Sea and the Bay of Bengal. These observations have proved to be immensely useful in the study of air-sea interaction processes over the Indian seas during the onset phase of the monsoon. During 2003, the summer monsoon set in over southeast Arabian Sea and Kerala on 8 June covering a part of south Bay of Bengal. Two deep ocean buoys, namely DS7 and DS2 were located south of the northern limit of the monsoon, whereas SW4, SW3 and SW1 were located north of the northern limit. The simultaneous observations of these five buoys have been utilized to determine the contrast between the air-sea interactions over the Arabian Sea and over the Bay of Bengal. All surface observations of the above-mentioned buoys in the Arabian Sea and four buoys in the Bay of Bengal (OB8, DS5, MB11 and MB12) have been analysed. The cruise track of ORV Sagar Kanya and the locations of meteorological buoys have been depicted in figure 1 .

\section{Results and discussion}

\subsection{Thermodynamical features over the Arabian Sea}

Earlier monsoon experiments have provided useful upper air observations from the sea areas which

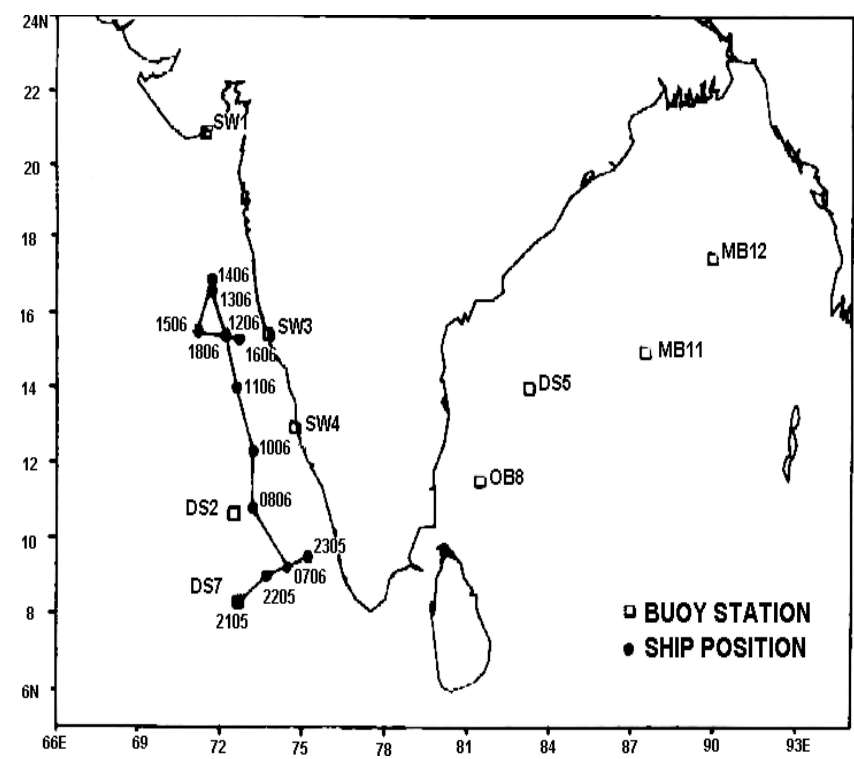

Figure 1. Cruise track of ORV Sagar Kanya (i.e., ship positions at different dates, 2105 indicates 21 May) and buoy locations during ARMEX-II (MB - Met Buoy, OB - Ocean Buoy, DS - Deep Sea Buoy, SW - Shallow Water Buoy). 
have enabled the study of some thermodynamical features during different phases of the monsoon (Seetharamayya and Master 1984; Singh 1992, 2004). Due to the importance of the thermodynamical state of the troposphere over the Arabian Sea before and after the onset of monsoon, special efforts were made to collect upper air observations during ARMEX.

A few thermodynamical features such as variation of height of zero degree isotherm (freezing level) and the temperature difference between 850 and $500 \mathrm{hPa}$ levels alongwith lower tropospheric winds obtained from the upper air observations of ORV Sagar Kanya have been presented in figure 2.

Figure 2 shows that the temperature difference between 850 and $500 \mathrm{hPa}$ attained maxima over the southeast Arabian Sea on 2 June, about a week before the monsoon onset over that area. Between 2 and 6 June, the temperature difference fell by

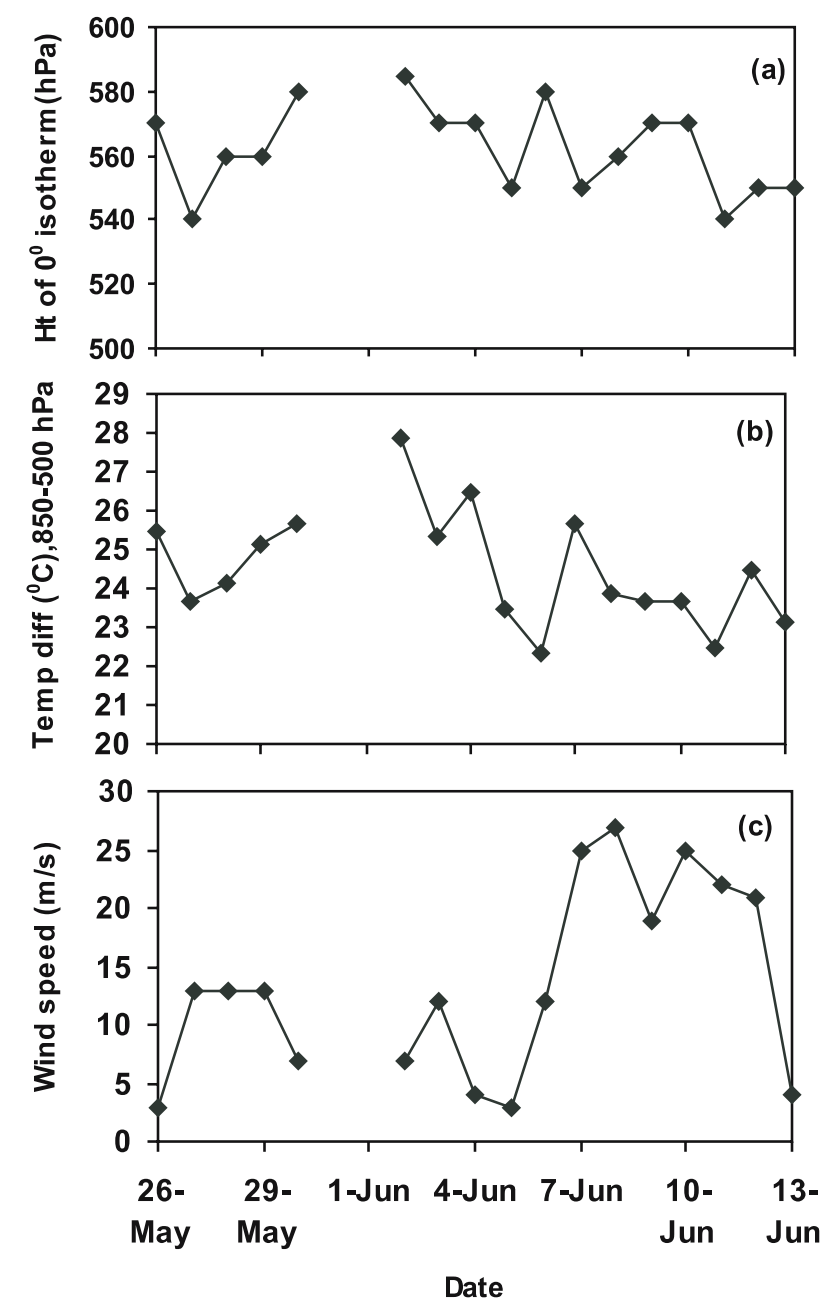

Figure 2. Thermodynamical characteristics of lower and middle troposphere over the Arabian Sea during the onset phase of monsoon (a) height of zero degree isotherm, (b) temperature difference between 850 and $500 \mathrm{hPa}$ and (c) wind speed at $850 \mathrm{hPa}$. about $6^{\circ} \mathrm{C}$ (figure $2 \mathrm{~b}$ ) just before the onset. Barring day-to-day fluctuations a general fall in the height of zero degree isotherm was observed till 2 June and slight increase thereafter till the monsoon onset on 8 June (figure 2a). The attainment of maximum temperature difference between 850 and $500 \mathrm{hPa}$ levels (lower and middle tropospheric levels) and a sudden general fall over the southeast Arabian Sea seems to be a useful precursor of the monsoon onset. Similarly, a reduction in the height of zero degree isotherm about a week before the monsoon onset is another precursor. The lower tropospheric winds at $850 \mathrm{hPa}$ started strengthening from 6 June and reached $25-30 \mathrm{~m} / \mathrm{s}$ on $7-8$ June at the time of onset (figure 2c). There were large day-to-day fluctuations in the wind speed even after the monsoon onset but the arrival of monsoon over the southeast Arabian Sea yielded sustained winds of $20-30 \mathrm{~m} / \mathrm{s}$ in the lower tropospheric levels $(850 \mathrm{hPa})$ for about a week.

\subsection{Air-sea interactions over the Arabian Sea and the Bay of Bengal}

Sea-air temperature differences obtained from ORV Sagar Kanya and the meteorological buoys in south Arabian Sea and the Bay of Bengal have been plotted in figures $3(\mathrm{a}-\mathrm{d})$. The SST-air temperature difference determines the exchange of sensible energy between ocean and atmosphere at the seaair interface. Positive difference indicates transport of heat energy from sea to air whereas negative difference is indicative of the transport of energy from air to sea. ARMEX data has shown that the air-sea interactions through exchange of sensible heat are entirely different over the south Arabian Sea and the south Bay of Bengal. There was a continuous transport of sensible heat from sea to air in the pre-onset and the onset phases of monsoon over the south Arabian Sea which is not true for the south Bay of Bengal region along the same latitude. ORV Sagar Kanya observations show that from 4-8 June, the SST-air temperature difference increased almost five times (from $0.5^{\circ} \mathrm{C}$ to $2.5^{\circ} \mathrm{C}$ ). This seems to be the effect of evaporative cooling caused by falling rain drops. After the monsoon onset on 8 June the temperature difference fell sharply. DS2 observations (figure 3b) show a sudden increase of SST-air temperature difference from 7 June onwards with the peak on 9 June. The location of DS2 was about 2 degrees north of Sagar Kanya position (figure 1) which may be the reason for a delayed maximum of SST-air temperature difference at DS2 location. The time lag of about 2 days may be due to the time difference between the rains at the ship and DS2 locations. Another factor that might have contributed to this is Sagar 
Kanya's location close to the coast on 9 June where SSTs were low due to coastal upwelling.

Figure 3(c-d) shows that the air-sea interaction over the Bay of Bengal was entirely different where air remained warmer than the sea throughout pre-onset and onset phases of the monsoon. The atmosphere imparted sensible heat to the sea over the Bay of Bengal and the buoyancy available at the sea-air interface over the south Arabian Sea was totally absent over the south Bay of Bengal. Thus the energy exchange processes at the sea-air
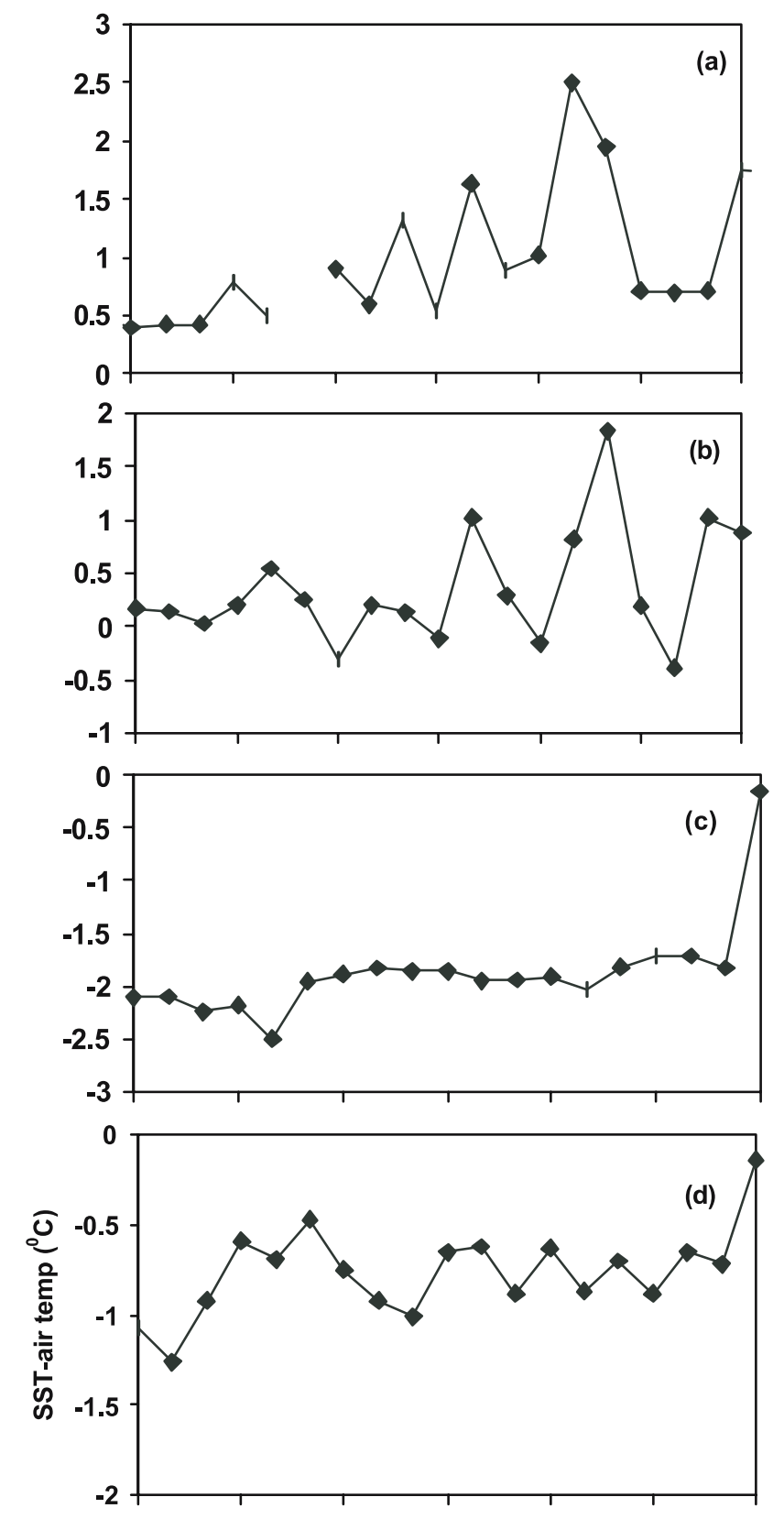

26-May 29-May 1-Jun 4-Jun 7-Jun 10-Jun 13-Jun Date

Figure 3. SST minus air temperature over the Arabian Sea and the Bay of Bengal (a) ORV Sagar Kanya, (b) DS2, (c) DS5 and (d) MB11. interface were different over the Arabian Sea and over the Bay of Bengal during the onset phase of monsoon.

\subsection{Surface features}

\subsubsection{South-north variations over the Arabian Sea}

Figure 4(a-d) shows the variations in the surface parameters like SST, wave height, surface wind speed and the sea level atmospheric pressure. The
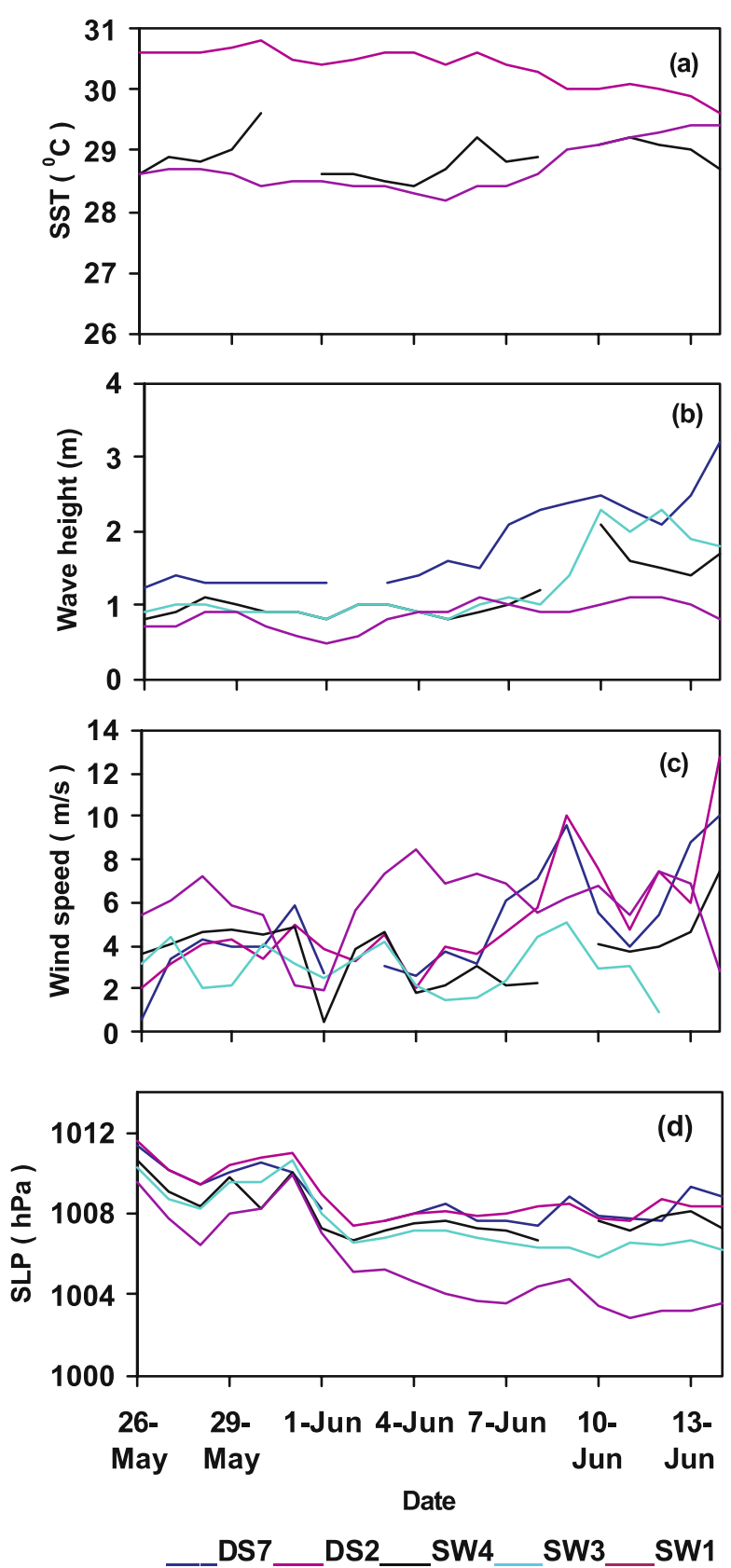

Figure 4. Latitudinal variation of surface parameters over the Arabian Sea (a) SST, (b) wave height, (c) wind speed and (d) SLP. 
main characteristic of SST variability during 2003 monsoon onset, in the warm pool region over south Arabian Sea was less than $0.5^{\circ} \mathrm{C}$ cooling between pre-onset and onset periods (figure 3a). The SSTs in the warm pool region continued to remain in excess of $30^{\circ} \mathrm{C}$ even after $5-6$ days of the monsoon onset (DS2) which is an unusual feature. Figure 4(a) contains several interesting features of SST variability in the Arabian Sea during the onset phase of the summer monsoon. For instance, the prevalence of high north-south SST gradient between SW4 and DS2 locations (i.e., latitudes $13^{\circ}$ and $11^{\circ} \mathrm{N}$ ) with SST difference of more than $2^{\circ} \mathrm{C}$ during the pre-onset period is an interesting aspect revealed by the ARMEX data. North-south SST gradient reached its peak a few days before the onset, i.e., on 4 June. After the monsoon onset on 8 June the gradient decreased considerably. This was partly due to the 3 days difference between the arrival of monsoon at DS2 and SW4 and partly due to the lesser impact of monsoon current on SSTs north of the warm pool region. However, a part of this high north-south SST gradient may be due to lower SSTs caused by coastal upwelling at SW4 location.

Figure 4(b and c) shows that the swells (wave height) arrived at least 2-3 days before the monsoon winds over the Arabian Sea. There was more sustained impact of monsoon on the roughness of the sea. From 7 June onwards the wave heights over the entire Arabian Sea region from DS7 to SW3 were between 2 and $3 \mathrm{~m}$ showing an increase of about $1 \mathrm{~m}$ between pre-onset and onset period.

Figure 4(d) brings out some interesting aspects of the sea level pressure variability over the Arabian Sea during the onset phase of the summer monsoon. Most important of these is the highest sea level pressure in the warm pool region (DS7 and DS2) in the entire Indian seas region during the pre-onset and onset periods. However, high SSTs in the warm pool region do show some impact on the surface air pressure due to which the SLP gradient in the pre-monsoon (May) was south to north i.e., SLP was lower at DS7 and higher over DS2 which was reversed after the onset. High SLPs in the warm pool region during 2003 monsoon onset phase might have inhibited the formation of the onset vortex. The Arabian Sea warm pool is a typical counter example to the common perception that higher SSTs cause more cyclogenesis. It appears that higher SSTs in the warm pool region occurred due to suppressed convection (Waliser et al 1993).

\subsubsection{Longitudinal variation}

The variations of surface parameters from south Arabian Sea to south Bay of Bengal (figure 5(a-d))
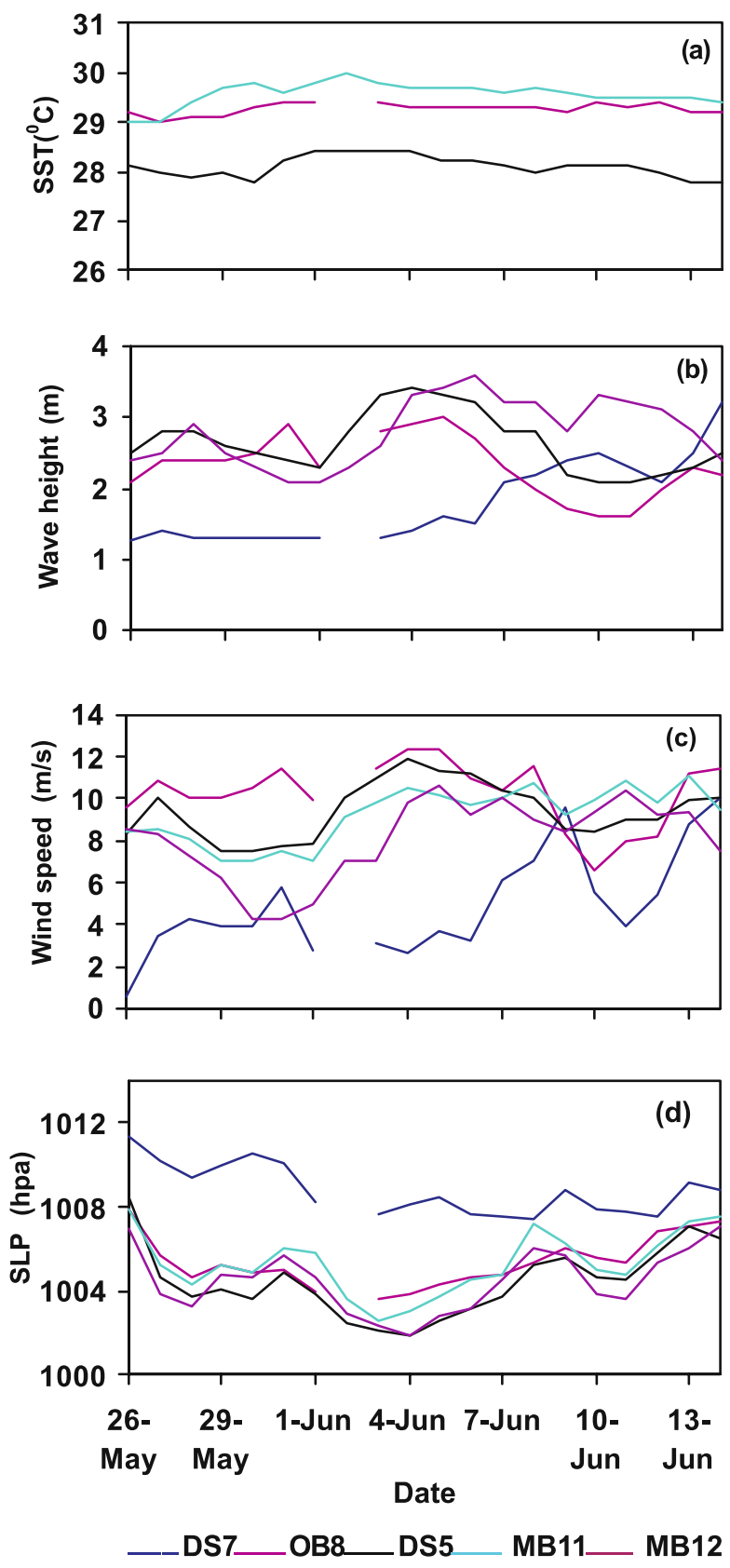

Figure 5. Longitudinal variation (a) SST (b) wave height, (c) wind speed and (d) SLP.

have brought out several interesting features. The onset of monsoon caused very little cooling of the south Bay of Bengal and there was hardly $0.2-0.3^{\circ} \mathrm{C}$ difference in the SSTs before and after the advance of monsoon over south Bay of Bengal. The SST in the south Bay of Bengal reached its maximum of $30^{\circ} \mathrm{C}$ on 3 June. In about one week's time i.e., from 26 May-3 June, SSTs increased by $1^{\circ} \mathrm{C}$ (from $29^{\circ} \mathrm{C}$ to $30^{\circ} \mathrm{C}$ ) and remained in excess of $29.5^{\circ} \mathrm{C}$ even after one week of monsoon advance over the south Bay of Bengal on 8 June (figure 5a). The suppressed cooling of Indian seas during the onset seems to be the 
main surface feature of the 2003 monsoon onset. Thus the dramatic fall of SSTs should be expected only when the onset is accompanied by the onset vortex.

Figures 4(a and $\mathrm{d})$ and $5(\mathrm{a}$ and $\mathrm{d})$ show that the Arabian Sea warm pool was the warmest region with the highest sea level pressure in the entire Arabian Sea and the Bay of Bengal during the period from 26 May to 14 June 2003. A comparison of figures $4(\mathrm{~b}$ and $\mathrm{c})$ and $5(\mathrm{~b}$ and $\mathrm{c})$ show that during 2003 monsoon onset, the winds were stronger and the waves were higher over the south Bay of Bengal as compared to those over the south Arabian Sea.

\section{Conclusions}

This study has shown that:

- The height of zero degree isotherm and the temperature difference in the atmospheric layer between 850 and $500 \mathrm{hPa}$ over the southeast Arabian Sea reached their maximum values about a week before the summer monsoon onset over Kerala.

- There was a large flux of sensible heat from sea to air over the southeast Arabian Sea just before the monsoon onset. Interestingly, over the south Bay of Bengal the transport of heat was from air to sea during pre-onset and onset phases. Thus the air-sea interactions were entirely different over the south Arabian Sea and the south Bay of Bengal inspite of the fact that both the areas were covered by the monsoon almost simultaneously.

- The warm pool region in the southeast Arabian Sea was dominated by not only the highest SSTs but also highest sea level pressure in the entire Indian seas region during the monsoon onset phase. This may be the reason for nonformation of onset vortex during 2003. However, the cause-effect relationships in the warm pool region need to be established through proper numerical simulations.

- The surface winds were stronger and the waves were higher over the south Bay of Bengal as compared to those over the south Arabian Sea during 2003 monsoon onset establishing the feeble character of the Arabian Sea branch of the onset current.

- North-south SST gradient over the southeast Arabian Sea reached its peak a few days before the monsoon onset over Kerala. The north-south SST gradient over the Arabian Sea diminished rapidly after the onset.

\section{Acknowledgements}

The authors are thankful to the Director General of Meteorology for permission to publish this paper. We also thank the scientific team of ARMEX, especially the ORV Sagar Kanya team and the Buoy network team of NIOT for oceanic data used in the present work. The staff of Monsoon Activity Centre and Climate Research Unit of Environment Monitoring \& Research Centre, India Meteorological Department, New Delhi are also thanked.

\section{References}

Chowdary J S, Gnanaseelan C, Thomas B, Sinha S K and Salvekar P S 2005 Response of Arabian Sea to the local forcing during 2003 pre-monsoon warming phase; Mausam 56 175-186.

Gnanaseelan C, Thomas B, Chowdary J S and Salvekar P S 2005 Evolution and collapse of Arabian Sea warm pool during two contrasting monsoons 2002 and 2003; Mausam 56 187-200.

Gopala Reddy K, Bharathi G, Sree Ram P, Subramanyam M V and Muni Krishna K 2005 The variation of surface heat fluxes during Arabian Sea monsoon experiment; Mausam 56 257-262.

Hareesh Kumar P V, Madhusoodanan P, Ajai Kumar M P and Raghunadha Rao A 2005 Characteristics of Arabian Sea mini warm pool during May 2003; Mausam 56 169-174.

Kershaw R 1985 Onset of southwest monsoon and SST anomalies in the Arabian Sea; Nature 315 561-563.

Krishnamurti T N, Ardanuy P, Ramanathan Y and Pasch R 1981 On the onset vortex of the summer monsoon; Mon. Weather Rev. 105 344-363.

Murthy B S and Sivaramakrishnan S 2005 Surface fluxes over Goa during Indian monsoon; Mausam 56 251-256.

Pearce R P and Mohanty U C 1984 Onset of the Asian summer monsoon 1979-1982; J. Atmos. Sci. 41 16201639.

Seetharamayya P and Master A 1984 Observed air-sea interface conditions in a monsoon depression during Monex 79; Arch. Met. Geoph. Biokl. A33 61-67.

Shenoi S C, Shankar D, Gopalkrishna V V and Durand F 2005 Role of ocean in the genesis and annihilation of the core of the warm pool in the southeastern Arabian Sea; Mausam 56 147-160.

Sikka D R 2005 From the International Indian Ocean Experiment (IIOE) to the Arabian Sea Monsoon Experiment (ARMEX) - four decades of major advances in monsoon meteorology; Mausam 56 19-36.

Singh O P 1992 Surface fluxes and cyclogenesis over north and adjoining central Bay of Bengal during MONTBLEX-90; Mausam 43 399-402.

Singh O P 2004 Dynamics of monsoon trough over northwest and adjoining westcentral Bay of Bengal; Mausam $55229-236$.

Singh O P and Hatwar H R 2005 Response of sea state to the monsoon onset; Mausam 56 59-64.

Waliser D A, Graham N E and Gautier C 1993 Comparison of high reflective cloud and outgoing longwave radiation datasets for use in estimating tropical deep convection; J. Climate 6 331-353. 